\title{
Retrospectiva do programa de atividade física do CDS/UFSC oferecido à pessoa idosa
}

\author{
Marize Amorim Lopes \\ marize.amorim@ufsc.br \\ Tania Rosane Bertoldo Benedetti \\ tania.benedetti@ufsc.br
}

\section{Resumo}

O Centro de Desportos da UFSC vem oferecendo atividades físicas para pessoas idosas desde 1985. Este estudo objetiva resgatar a trajetória das atividades e relatos de experiências ao longo dos 28 anos de trabalho. Os resultados sugerem que este projeto de extensão tem proporcionado aos idosos um melhor domínio corporal, estimulando neles mudanças a favor de hábitos de vida mais saudáveis. No meio acadêmico, tem favorecido o ensino e a pesquisa na área da educação física e gerontologia; na extensão, vem promovendo o intercâmbio entre gerações e da universidade com a comunidade.

Palavras-chave: Pessoa idosa. Atividade física. CDS. UFSC.

\section{Retrospective of the physical activity program of CDS/UFSC offered to the older adults}

\begin{abstract}
The Sports Centre of UFSC has been offering physical activities for older adults since 1985. This study aims to disseminate the trajectory of the activities and the experience gained over 28 years of work. The results suggest that this extension project has provided seniors with a better body control, stimulating changes in their behavior in favor of healthier lifestyles. In academia, it has contributed to teaching and research in the area of physical education and gerontology; in extension programs, has promoted exchanges among generations and between the university and the community.
\end{abstract}

Keywords: Older adults. Physical activity. CDS. UFSC. 


\section{Extensio $\mid$ Relato de Experiência}

\section{INTRODUÇÃO}

O processo de envelhecimento populacional e o consequente crescimento da população idosa é um fenômeno mundial e engloba todas as camadas sociais, culturais ou econômicas. Dados recentes do Censo Demográfico (IBGE, 2010) evidenciam que o Brasil tem 12\% de pessoas com idade acima de 60 anos, fato que tem levado autoridades e pesquisadores a buscarem estratégias de promoção da saúde e prevenção de doenças, particularmente as crônicas, que acometem a população idosa.

A promoção da saúde e a prevenção das doenças buscam a manutenção da capacidade física e funcional, que estão diretamente associadas à sua qualidade de vida (FRANK et al., 2007; NETO; CASTRO, 2012). Nesse contexto, a Organização Mundial de Saúde (OMS, 2005) relaciona o termo envelhecimento ativo não somente à manutenção da capacidade física, mas também à participação ampla nas dimensões sociais, econômicas, espirituais e civis, à saúde e à segurança.

A meta de envelhecer com qualidade de vida é uma busca constante do ser humano, e sua preparação para a etapa da velhice deve ser trabalhada desde a tenra idade. Muitos idosos, ao entrarem no processo de envelhecimento, percebem as perdas ocasionadas pela própria idade e se acomodam (LOPES, 2012); mas, para mudar essa concepção, é necessário que se mude primeiramente a consciência do próprio idoso (ou pessoa de meia idade), o qual se descrimina e não se valoriza.

A atividade física executada por toda a vida comprovadamente é um meio de ter uma melhor saúde, autoestima, entre tantos outros fatores positivos que ela ocasiona (CHODZKO-ZAJKO et al., 2009). Além disso, ela favorece a mudança comportamental e ainda pode desencadear transformações sociais, mesmo quando se começa a praticá-la mais tarde. A manutenção do corpo em atividade é fundamental para preservar as funções vitais em bom funcionamento, favorecendo um melhor desempenho das atividades da vida diária. As pessoas longevas, ao praticarem atividades físicas com regularidade e orientação médica, quando comparadas as de vida ociosa, mostram melhor adaptação orgânica aos esforços físicos, além de maior resistência às doenças e ao estresse emocional e ambiental. Isso pode ser percebido conforme os estudos que vêm sendo realizados pelos profissionais e acadêmicos que atuam no Centro de Desportos da Universidade Federal de Santa Catarina (UFSC), publicados em forma de TCCs, dissertações, teses, artigos (LOPES, 2012; MAZO et al., 2012; HOEFELMANN et al., 2011; CIPRIANI et al., 2010; MAZO; LOPES; BENEDETTI, 2009).

Este trabalho que o Centro de Desportos vem realizando desde 1985 com os idosos é reconhecido e apontado pela comunidade de Florianópolis como um meio de promover a manutenção da qualidade de vida dos idosos. A grande procura e o baixo índice de evasão evidenciam a serenidade e responsabilidade de atuação dos profissionais e acadêmicos.

A prática de atividade física para pessoas idosas deve envolver um trabalho multiprofissional, pois as trocas de informações e experiências favorecem a melhor adequação das atividades direcionadas a essa faixa etária. $\mathrm{O}$ trabalho físico voltado à pessoa idosa deve atingir seus anseios, necessidades e suas condições físicas. $\mathrm{O}$ corpo em movimento é sinal de saúde, autonomia e alegria.

O Programa de Atividade Física para a Terceira Idade, realizada em forma de projeto de extensão, vem realizando ensino e pesquisas que buscam melhorar e inovar as técnicas de trabalho com a pessoa idosa, permitindo ao profissional uma melhor atuação, bem como uma participação efetiva ao idoso em sua comunidade, como cidadão atuante. A extensão, ensino e pesquisa se fazem presentes neste projeto, envolvendo acadêmicos de graduação e pós-graduação de diversas áreas.

Acreditando-se na importância de disponibilizar e divulgar as experiências sucedidas nesses 28 anos de trabalho com idosos, bem como a trajetória do trabalho desenvolvido com a Terceira Idade pelo Centro de Desportos da UFSC, propõe-se um estudo buscando documentar a realização do projeto de extensão "Atividades Físicas para a Terceira Idade do Centro de Desportos", criado em 1985, possibilitando, assim, a criação de um acervo acadêmico útil para estudantes, pesquisadores e profissionais da área de atividade física e envelhecimento. 


\section{MATERIAIS E MÉTODOS}

Este estudo se caracterizou como uma pesquisa de levantamento histórico do período de 1985 a 2013 do "Programa de Atividade Física para a Terceira Idade", aplicando-se a análise de conteúdo do tipo descritivo-exploratória. Os instrumentos utilizados foram: entrevistas informais, registro, fotos, artigos, livros, reportagens, imagens e vídeos. Buscou-se a captação das informações com os profissionais envolvidos no projeto, acesso às bibliotecas, jornais e setores de informação da UFSC.

\section{Retrospectiva da Implantação das Atividades Físicas para Pessoas Idosas no Centro de Desportos}

A atividade física com pessoas idosas na UFSC começou no Centro de Desportos (CDS) em 1985. O Núcleo de Estudos da Terceira Idade (NETI) procurou o CDS para averiguar a possibilidade de desenvolver um trabalho junto aos idosos na área da atividade física. Após os primeiros contatos, professores da área da recreação e ginástica foram convidados a participarem e a se engajarem nessa atividade em parceria com o NETI.

A efetivação do projeto aconteceu em agosto de 1985 com a professora Marize Amorim Lopes, que assumiu de fato a coordenação e a orientação das atividades físicas para a pessoa idosa. A escassez bibliográfica e a falta de experiência na área da atividade física e gerontologia dificultaram as primeiras decisões.

As atividades foram vinculadas a um projeto de extensão que foi intitulado "Atividade Física para a Terceira Idade". O grupo inicialmente era pequeno (cinco idosas), que frequentavam o encontro com roupas inadequadas (usavam saias, vestidos) à prática de atividade física.

A preocupação imediata era esclarecer e conscientizar os idosos dos benefícios e da importância do trabalho a ser desenvolvido. As atividades iniciais buscavam a conscientização corporal esquecida com as atribuições das atividades da vida diárias (AVDs). O objetivo primordial era estimular e fortalecer os grupos musculares e articulações, de forma cautelosa, para que todas pudessem realizar as atividades físicas propostas e adequadas a essa faixa etária, bem como incentivar o contato socioafetivo.

O grupo foi ampliado e exigiu-se uma avaliação médica, que deveria ser realizada preferencialmente pelo médico que acompanhava o próprio idoso. A preocupação inicial era sempre mostrar a importância da prática regular de atividade física para a manutenção de uma vida mais saudável, levando a pessoa idosa à aquisição de novos hábitos de vida que primassem por melhor qualidade de vida.

Teve-se sempre o cuidado de não exigir mudanças de comportamentos e de hábitos das pessoas idosas, como, por exemplo: cobrança de uso de calça ou bermuda para realização das atividades. Essas exigências poderiam afugentá-las e até mesmo impedir que participassem das atividades. Vestiam normalmente saias e vestidos, que faziam parte de seu cotidiano. As mudanças com relação às vestimentas aconteceram gradativamente e naturalmente pela própria exigência da prática e do conforto na realização das atividades físicas.

As primeiras mudanças foram: o uso de bermuda e/ou calça, que a principio era trazida para trocar e usar apenas nas aulas. Após um tempo, começou a fazer parte do seu vestuário habitual. Foi também incorporado o uso de tênis, meia soquete e até polaina. Após um ano de atividades, resolveram usar colante (malha preta utilizado no balé) para apresentação de uma dança com movimento ginástico, que foi desenvolvida por elas, em um evento do Centro de Desportos (jogos que integravam as atividades da disciplina de Prática Desportiva). Muitas não gostaram, achando que ficariam horrorosas; mas, para surpresa de todas, se sentiram bem e perceberam que seu corpo não ficava feio numa veste justa. A partir daí, vestiram roupas justas sem preconceitos. Foi criado um uniforme com as cores da UFSC (azul e amarelo), que a maioria o adotou e adota até os dias de hoje para realizar as atividades físicas oferecidas no programa. 
A ampliação da turma foi gradativa: a resistência à prática de atividade física era muito forte do ilhéu catarinense, por não fazer parte dos costumes socioculturais da colonização portuguesa com base açoriana. Um ano e meio após a criação, a turma passou a ter quarenta alunos. Toda divulgação se deu por conta dos próprios participantes.

A expansão dessa atividade no Centro de Desportos e na comunidade universitária se deu sempre de forma lenta, e gradativamente novos espaços foram sendo ocupados.

Uma reportagem feita pelo Jornal Santa Catarina em 20 de maio de 1987 divulgou, pela primeira vez, o trabalho na mídia. Foi também a primeira participação do grupo no encontro de idosos realizado pelo SESC de São Paulo em Santos.

Os efeitos do trabalho estavam sendo evidenciados pelos próprios idosos e pela mídia. A integração do grupo era visível. A procura pelas atividades cresceu, havendo a necessidade de se criar mais uma turma. Aos poucos outras professoras do Centro de Desportos foram se agregando ao trabalho, sendo elas: Yuta Falqueto e Clarice Tomasi Soncini. Clarice iniciou atividades com bola, mas infelizmente nesta época houve pouca adoção e, após um ano de realização, foi desativada. Yuta ajudou na expansão das turmas de ginástica. Com o apoio da professora, em 1987 criaram-se mais duas turmas, as quais assumiu até a sua aposentadoria.

Em 1989 ocorreram algumas mudanças, como: a criação de mais uma turma de ginástica, a inclusão das primeiras avaliações da aptidão física e medidas antropométricas, que tinham como meta avaliar os efeitos das atividades físicas no programa desenvolvido. As avaliações levavam em conta a capacidade funcional do indivíduo, possibilitando que o praticante analisasse o seu progresso a fim de obter melhores resultados.

Para o desenvolvimento dessas avaliações, obteve-se a colaboração do professor Nelson da Silva Aguiar. Essas avaliações físicas foram reestruturadas ao longo do tempo conforme as pesquisas foram avançando, e atualmente utiliza-se a bateria teste desenvolvida à população idosa, como a da Rikle e Jones (1999), que é realizada nos meses de março e novembro de cada ano, para que o idoso saiba se progrediu em sua aptidão física anualmente ou entre os anos.

O programa passa a oferecer três turmas, funcionando de segunda a sexta no período matutino, atingindo aproximadamente 100 pessoas idosas. Observou-se, contudo, que a procura pelas aulas oferecidas no programa era por maioria de mulheres idosas. Os homens, mesmo sendo convidados, não apareciam. Surgiu-se então a ideia de criar uma turma masculina de atividades físicas, mas não vingou. Os homens não aderiram.

Neste ano também foi iniciado um trabalho de atividade física junto aos idosos do Asilo Irmão Joaquim. Houve o envolvimento dos acadêmicos do curso de Licenciatura em Educação Física em forma de estágios curriculares e extracurriculares nas atividades físicas do programa.

Foi criado o Grupo de Dança Folclórica da Terceira Idade da UFSC, com o objetivo de divulgar e recriar as danças de etnia portuguesa com base açoriana. Para esse trabalho, teve-se a participação da professora Ivete Ouriques Quint.

É interessante destacar que o envolvimento dos idosos por meio de sua história de vida tem contribuído para ampliar as conquistas, oportunizando danças que retratam a realidade sociocultural do povo do litoral catarinense, fato esse necessário para a montagem coreográfica que sempre envolveu pesquisas históricas.

Em 1990 foi lançado o livro Danças Folclóricas da Ilha de Santa Catarina, de autoria de Ivete Ouriques Quint, Marisa Gularte e Marize Amorim Lopes, todas professoras do Centro de Desportos da UFSC. Esse livro, juntamente com o Grupo de Dança, tornou-se referência na área da cultura do ilhéu e litoral catarinense, sendo conhecido em âmbito municipal, estadual, nacional e internacional.

Nesse mesmo período, foi ampliada a participação da figura masculina com a criação de uma turma para casais. A professora Ivete Ouriques Quint ministrava aulas nessa turma até a sua aposentadoria. A partir daí, o número de idosos do sexo masculino vem aumentado constantemente, embora as mulheres sejam a grande maioria. Atualmente, o programa tem em torno de $20 \%$ de homens. 
O trabalho conseguiu grande projeção. O programa era e continua sendo procurado pela imprensa escrita e televisionada para reportagens sobre idosos, saúde e atividade física. É reconhecido em diversas áreas e recomendado por vários médicos. Acadêmicos de diferentes cursos procuraram o programa para realizarem seus trabalhos de conclusão de curso e/ou ter experiência com os idosos, fortalecendo dessa forma o tripé universitário: ensino, pesquisa e extensão.

Em 1993 foi criada mais uma turma no período vespertino e, em 1995, com a vinda da professora Tânia Bertoldo Benedetti, que já tinha experiências com idosos, foi criada mais uma turma no período vespertino, atingindo-se sete turmas. Neste ano, com a aposentadoria da professora Ivete, foi necessária a ampliação do envolvimento acadêmico do Curso de Licenciatura em Educação Física para ministrar as atividades no programa. O projeto foi contemplado com bolsistas pelo Departamento de Assuntos de Extensão, vinculado à Pró-Reitoria de Cultura e Extensão, como era denominado na época.

Em 1996, iniciamos o trabalho junto às comunidades próximas à UFSC. Os trabalhos iniciaram nas comunidades da Serrinha e Santa Mônica (coordenado atualmente pela Prefeitura Municipal de Florianópolis), bem como a implantação de um programa com doentes crônicos da Policlínica de Referência Regional Centro (SUS), que até hoje persiste com a coordenação da própria policlínica. Foi um trabalho multiprofissional que envolveu, além do profissional de educação física, enfermeiros, assistentes sociais, médicos, nutricionistas e, ainda, estagiários acadêmicos do Curso de Licenciatura em Educação Física, contratados pela Secretaria da Saúde do Estado.

Neste mesmo ano, foram ampliadas as atividades no Centro de Desportos, em virtude da demanda. Criaram-se mais quatro turmas de ginástica em parceria com o projeto de extensão Sábado no Campus, coordenado pelo professor Luciano Lazzaris Fernandes, ficando o programa com 11 turmas nas dependências da UFSC.

Com base no trabalho desenvolvido com os idosos, lançou-se em 1997 o livro Hidroginástica e Ginástica Participativa na Terceira Idade, de autoria de Marize Amorim Lopes, Sidney Ferreira Farias e Edison Roberto de Souza, professores do CDS. As publicações em anais de eventos científicos começaram a ser intensificadas à medida que o conhecimento científico aumentava. Cada vez mais intenso foi a participação em eventos, sejam eles de abrangência local, regional, estadual, nacional ou internacional. Nestes locais, eram abordadas, por meio de estudos, as experiências com os idosos do programa.

A partir de 2000, com a construção da piscina térmica no Centro de Desportos, foram oferecidas atividades aquáticas, sendo criadas duas turmas de hidroginástica e uma de natação com a coordenação da professora Tania Bertoldo Benedetti. Neste ano, também, os idosos foram convidados a participarem do I Jogos de Integração do Idoso (JIIDO), que levou à criação da turma de vôlei adaptado.

O projeto passa a ser denominado "Programa de Atividade Física e Dança Folclórica para a Terceira Idade do CDS/UFSC", e os idosos começam a se projetar na área dos esportes adaptados participando dos I, II, III e IV JIIDO, nas fases municipais, estaduais e da região Sul.

Em 2001 o Grupo de Dança da Terceira Idade da UFSC lança o seu primeiro CD, contendo seis músicas da cultura do ilhéu e litoral catarinense. Neste mesmo ano, as professoras Marize Amorim Lopes, Tânia Bertoldo Benedetti, que coordenam este projeto, em parceria com a professora Giovana Zarpellon Mazo da Universidade de Desenvolvimento do Estado de Santa Catarina (UDESC), lançam o livro "Atividade Física: concepção gerontológica”, com 238 páginas, que revela as experiências das professoras com as pessoas idosas. Esgotada a primeira edição, em 2004 lançou-se a segunda edição, revisada e ampliada para 247 páginas, e em 2009 a terceira edição, revisada e ampliada para 318 páginas. Esse livro atualmente é referência nos cursos de graduação em Educação Física e, em muitas universidades brasileiras, é consulta básica para ingresso em mestrados e doutorados.

Em 2005, a convite da Associação de Parkinson/SC, criou-se um novo projeto de extensão para envolver pessoas portadoras de distúrbios de movimentos abrangendo pessoas portadoras de Parkinson e Machado Joseph, intitulado "Vivências Corporais para Portadores de Distúrbios de Movimento". Ainda neste ano, o Grupo de Dança Folclórica da Terceira Idade da UFSC lança o DVD, que compila as danças de 


\section{Extensio $\mid$ Relato de Experiência}

maior repercussão com o objetivo de registrar o acervo sociocultural dançante do litoral catarinense.

O Curso de Licenciatura e Bacharelado em Educação Física do Centro de Desportos, em suas modificações curriculares de 2006, incluiu a disciplina obrigatória "Envelhecimento, Atividade Física e Saúde”, com 54 créditos, na $6^{\text {a }}$ fase; e passa a oferecer a disciplina optativa "Seminário de aprofundamento em atividade física e saúde”, que discute o Sistema Único de Saúde (SUS) na Educação Física, preparando os alunos para intervenção com pessoas portadoras de doenças crônicas que procuram as Unidades Básicas de Saúde, dentre elas, o maior número é de idosos. Vem se oportunizando, assim, conhecimentos sobre envelhecimento humano que certamente contribuem para a prática profissional qualificada e contextualizada. Em 2006 é também criado o projeto "Envelhecimento Ativo" nas Unidades de Saúde (UFSC-UDESC). Esse programa mudou o nome e com maior abrangência passa a ser denominado Floripa Ativa (ginástica) junto à Secretaria de Saúde e de Assistência Social de Florianópolis envolvendo 10 Unidades de Saúde nas comunidades: Córrego Grande, Saco Grande, Lagoa da Conceição, João Paulo, Ingleses, Continente, Fazenda do Rio Tavares, Rio Tavares, Prainha, Trindade.

Em 2009 é lançado o DVD intitulado "Atividades físicas e o idoso: propostas inovadoras” compilando todas as atividades desenvolvidas do projeto e as experiências profissionais destes anos de trabalho com a pessoa idosa, de autoria de Marize Amorim Lopes e Amanda Pacheco Beck.

A partir de 2010, foi inserida a Educação Física no grupo Programa de Educação pelo Trabalho (PET) - Saúde da Família. Os acadêmicos de Educação Física começam a atuar como bolsistas nos Centros de Saúde. Foi realizado pela Federação Estadual de Esportes (FESPORTE) o primeiro Jogos Abertos da Terceira Idade de Santa Catarina (JASTI), com as modalidades: dança coreografada, dança de salão, bolão, bocha, dominó, truco e canastra. Os idosos do projeto são estimulados a participarem das fases municipal, regional e estadual. Cria-se a turma de Jogos Coletivos Adaptados envolvendo as modalidades: câmbio, basquete reloginho e handebol por zona. Nesse período também são oferecidas uma linha de pesquisa de envelhecimento e atividade física no programa de pós-graduação em Educação Física, mestrado e doutorado, na área de atividade física relacionada à saúde.

Em 2010 realizou-se uma festa comemorativa aos 25 anos do projeto no Centro de Eventos. Buscou-se homenagear todos os profissionais que contribuíram para essa trajetória do projeto e os idosos que permanecem e que contribuem para a continuidade deste trabalho.

Em 2012 é criado o Grupo de Mudança de Comportamento nos Centros de Saúde - VAMOS: Vida Ativa Melhorando a Saúde, que no momento é testado e em breve será mais um programa que se originou na universidade e contribui com o conhecimento científico na melhoria da qualidade de vida da população idosa.

Em 2012 e 2013, o envelhecimento humano é discutido nas disciplinas da pós-graduação em Educação Física e Nutrição. São organizados seminários para a graduação e pós-graduação em Educação Física, bem como oferecidos cursos de aprofundamento na área de envelhecimento. Foram defendidas duas teses, 25 dissertações e inúmeros TCC sobre envelhecimento e atividade física. Há diversos projetos de pesquisa em andamento, sendo três com financiamento. Publicaram-se quatro livros, mais de 100 artigos científicos na área, mais de 10 capítulos de livros e inúmeros resumos publicados em anais.

Para finalizar a cronologia do trabalho realizado, destaca-se que, de 1985 a 2013, atuaram no projeto 87 bolsistas, todos acadêmicos do curso de Licenciatura e Bacharelado em Educação Física e nove professores de Educação Física, todos lotados no Departamento de Educação Físicas do Centro de Despostos.

\section{Percurso Metodológico das Atividades Desenvolvidas no Projeto}

As atividades são desenvolvidas seguindo o calendário da UFSC. Iniciam em março, com o primeiro semestre, e finalizam em dezembro, com o segundo semestre letivo. É exigida uma avaliação clínica das pessoas idosas participantes, havendo necessidade de apresentarem um atestado médico para frequentarem 
o programa. São realizadas algumas medidas antropométricas (massa corporal, estatura, circunferências de cintura e quadril) e avaliações físicas aplicando alguns testes de aptidão e habilidade motora. Para este último caso, utiliza-se a bateria de testes de Aptidão Física Funcional de Idosos "Senior Fitness Test (SFT)" de Rikli e Jones (1999), que oferece suporte para o acompanhamento das atividades que serão desenvolvidas, como: força dos membros inferiores (MI) e superiores (MS), capacidade aeróbia, flexibilidade dos MI e MS, agilidade motora e equilíbrio dinâmico.

O referido projeto atende a pessoas a partir de 60 anos, de ambos os sexos, duas a três vezes por semana, durante 50 a 60 minutos, com sessões de ginástica, dança, vôlei adaptado, hidroginástica, natação e recreação. As atividades desenvolvidas objetivam estimular o corpo em sua totalidade, como, por exemplo: exercício sensório motor envolvendo trabalhos aeróbios, de alongamento, flexibilidade, equilíbrio, força, resistência, relaxamento, dança, entre outros; nunca se esquecendo de que são adequados aos interesses e principalmente às condições físicas, possibilidades e necessidades do grupo e da própria pessoa idosa.

Durante as atividades físicas que são desenvolvidas, são utilizadas músicas, a fim de possibilitar maior interesse e prazer de realização. Os materiais utilizados variam desde alguns reciclados até materiais da ginástica, como: bolas, arcos, cordas, halteres, pesos, step, caneleiras, elástico, entre outros; com o intuito de promover a adoção das pessoas idosas pelas atividades oferecidas.

As modalidades que são oferecidas aos idosos são retratadas no Quadro 1.

Quadro 1 - As atividades físicas oferecidas aos idosos no CDS/UFSC e na comunidade de Florianópolis, 2013

\begin{tabular}{|l|c|c|c|c|}
\hline \multicolumn{1}{|c|}{ Modalidade } & Local & $\begin{array}{c}\text { Frequência } \\
\text { por semana }\end{array}$ & N. de turmas & N. de pessoas \\
\hline Ginástica Mista & UFSC & 3 & 4 & 126 \\
\hline Ginástica Mista & UFSC & 2 & 5 & 294 \\
\hline Ginástica Mista & Serrinha & 2 & 1 & 15 \\
\hline Grupo de Dança & UFSC & 2 & 1 & 20 \\
\hline Hidroginástica & UFSC & 2 & 2 & 50 \\
\hline Natação & UFSC & 2 & 1 & 15 \\
\hline Vôlei adaptado & UFSC & 2 & 1 & 12 \\
\hline $\begin{array}{l}\text { Dança de salão para } \\
\text { portadores de Parkinson }\end{array}$ & $\begin{array}{c}\text { Reabilitação do Hospi- } \\
\text { tal Joana de Gusmão }\end{array}$ & 2 & 2 & 30 \\
\hline $\begin{array}{l}\text { Musculação para porta- } \\
\text { dores de Parkinson }\end{array}$ & UFSC & 2 & 1 & 15 \\
\hline $\begin{array}{l}\text { Ginástica no Floripa } \\
\text { Ativa }\end{array}$ & Unidades de Saúde & 2 & 10 & 310 \\
\hline
\end{tabular}

A coordenação do programa incentiva as pessoas idosas do projeto a participarem de eventos científicos, palestras, encontros, seminários, atividades comemorativas (caminhadas ecológicas, palestras, jogos), Jogos Abertos da Terceira Idade (JASTI), etc. Os idosos ajudam na organização de eventos e se engajam em atividades de seu interesse.

Os bolsistas que atuam neste projeto participam do Grupo de Estudos sobre Cuidado de Saúde de Pessoas Idosas (GESPI), o qual tem como objetivo geral orientar e planejar as atividades semanais, fomentar pesquisas e debates da área gerontológica. Este grupo está vinculado ao Núcleo Interdisciplinar de Pesquisa, Ensino e Assistência Geronto-Geriátrica, que funciona no HU.

A produção de conhecimentos no GESPI desenvolve estudos de avaliação multidimensional de diferentes extratos da população idosa; estudos de expectativas e necessidades dos idosos usuários de serviços de saúde; construção de modelos e instrumentos para assistência, os quais têm sido testados e validados visando formular tecnologias assistidas e educacionais. 
A atuação dos profissionais e acadêmicos amplia-se a cada ano e, em 2013, além do trabalho com as pessoas idosas na UFSC e nas comunidades anteriormente citadas, destaca-se a participação na Rede Docente Assistencial (RDA), Residência Multiprofissional, Pró-Saúde, PET-Saúde da Samília, SEPEX, SEURS, JASTI, etc.

\section{CONSIDERAÇÕES FINAIS}

Após 28 anos de atuação do programa de atividades para pessoas idosas, é possível perceber o papel da universidade e do Centro de Desportes na vida dos idosos da grande Florianópolis. A procura e o baixo índice de evasão evidenciam qualidade e competência na atuação dos profissionais e acadêmicos.

A área de Educação Física e Gerontologia tem sido o centro de interesse dos acadêmicos de diferentes cursos da UFSC. Nessa instituição foram e são oportunizadas vivências acadêmicas nos programas, que despertaram o interesse sobre o envelhecimento humano. Essa nova área de estudo "Gerontologia" favoreceu a criação de disciplinas curriculares e optativas tanto na graduação como na pós-graduação das áreas acadêmicas.

Tratando especificamente do Curso de Licenciatura e Bacharelado de Educação Física, os avanços em estudos/pesquisas relativos na área da Educação Física e Gerontologia no meio acadêmico vêm ocorrendo de forma lenta e gradativa. Esse crescimento tem oportunizado à universidade oferecer aos acadêmicos o ensino, pesquisa e extensão, por meio de novos conhecimentos e vivências com idosos, despertando o interesse e possibilidades de um campo de atuação profissional.

O Curso de Educação Física do CDS, em suas modificações curriculares, vem oportunizando aos alunos uma formação direcionada a trabalhos com grupos especiais, servindo de campo de pesquisa e estágios. Outras disciplinas curriculares do curso de Licenciatura em Educação Física e de áreas também procuram o programa para desenvolver trabalhos, estudos e pesquisas na área gerontológica.

O constante interesse acadêmico em querer vivenciar atividades com pessoas idosas reflete resultados positivos, como os trabalhos de conclusão de curso na Educação Física, fato que tem ampliado a produção científica. Esses estudos vêm comprovando que o Programa de Atividade Física para a Terceira Idade favorece a melhoria na aptidão física, no domínio corporal, na autoestima, na disposição e autonomia dos idosos, e especialmente amplia as relações sociais. Os efeitos psicológicos contribuem para a redução da ansiedade e da depressão, e atua positivamente na regulação do sono, promoção do autoconceito, da autoestima e da autoconfiança.

A assiduidade dos frequentadores e o seu comprometimento com o projeto refletem a importância das práticas de atividade física oferecidas para essa faixa etária. O manuseio corporal vem contribuindo para a maneira de ser, pensar e agir das pessoas idosas que frequentam essas atividades. A amizade, cooperação e a forte união do grupo são constatadas por meio de suas atitudes presenciadas na rotina do Centro de Desportos.

A assiduidade dos frequentadores e o seu comprometimento com o projeto refletem a importância das práticas de atividade física oferecidas para essa faixa etária. A amizade, cooperação e a forte união do grupo são constatadas por meio de suas atitudes presenciadas na rotina do Centro de Desportos. O domínio do seu corpo contribui para o ser, pensar e agir.

O idoso ativo busca o movimento e experimenta mudanças corporais, o que ajuda na transformação das pessoas. A Educação Física hoje é vista como um elemento-chave no envelhecimento saudável e de qualidade. O idoso ativo busca sempre algo que o realize como ser. Movimentar-se e experimentar vivências corporais transforma as pessoas internamente. A Educação Física hoje é vista como um elemento-chave no envelhecimento saudável e de qualidade. As pessoas idosas buscam e almejam na velhice uma maior independência e autonomia.

A continuidade deste projeto desde 1985 tem proporcionado aos idosos uma prática de atividade 
física adequada às suas condições físicas, sendo capazes de exercerem suas atividades diárias, mesmo apresentando limitações próprias do envelhecimento humano.

Os resultados obtidos pelas avaliações dos testes de aptidão física e os trabalhos de TCC do Curso de Licenciatura e Bacharelado em Educação Física, das dissertações e teses demonstram os resultados positivos deste projeto na manutenção de sua saúde.

Observa-se, também, que este projeto de extensão tem favorecido o intercâmbio da universidade com a comunidade e a troca entre gerações. As conquistas da Educação Física vinculada à Gerontologia são oferecidas aos acadêmicos e profissionais de diferentes áreas para atuação com o ensino, pesquisa e extensão, despertando interesse acadêmico e novo campo de atuação profissional.

As conquistas e as dificuldades se fazem presentes no dia a dia, mas a forma de conduzir o trabalho de tamanha dimensão se concretiza com amor, respeito, carinho, perseverança e trocas. O comprometimento profissional de buscar sempre o melhor em seu campo de atuação favorece um envelhecimento com dignidade, disposição e vitalidade.

O trabalho da Educação Física por meio de atividades física aos idosos envolve outras áreas por meio de um trabalho multiprofissional.

O trabalho de atividade física é adaptado à pessoa idosa e visa atingir seus anseios, necessidades e condições físicas. O corpo do idoso em movimento é sinal de saúde e alegria. A UFSC, atenta a essa realidade, por meio do Centro de Desportos (CDS) em conjunto com outros setores universitários, vem priorizando esse trabalho, influenciando diretamente na qualidade de vida das pessoas idosas. Atuando há 28 anos com um grupo significativo de pessoas em idade avançada (de 60 a 97 anos), esse projeto de extensão tem proporcionado a prática de atividade física regular, visando possibilitar um envelhecimento ativo e de qualidade para seus participantes.

\section{REFERÊNCIAS}

CIPRIANI, N.C.S.; MEURER, S.T.; BENEDETTI, T.R.B.; LOPES, M.A. Aptidão Funcional de Idosas Praticantes de Atividades Físicas. Revista de Cineantropometria e Desempenho Humano. Florianópolis. v.12, n.2, p.106-111, 2010.

CHODZKO-ZAJKO, W. J.; PROCTOR, D.N.; SINGH, M.A.F.; MINSON, C.T.; NIGG, C.R.; SALEM, G.J.et al. American College of Sports Medicine position stand. Exercise and physical activity for older adults. Med Sci Sports Exerc.v.41, n.7, p.1510-1530, 2009.

FREITAS, C. M. S. M; SANTIAGO, M.S; VIANA, A.T; LEÃO, A.C; FREYRE, C. Aspectos motivacionais que influenciam a adesão e manutenção de idosos a programas de exercícios físicos. Revista Brasileira de Cineantropometria e Desempenho Humano. Florianópolis. v.9, n.1, p. 92-100, 2007.

HOEFELMANN, C.P.; BENEDETTI, T.R.B.; ANTES, D.L.; LOPES, M.A.; MAZO, G.Z.; KORN, S. Aptidão funcional de mulheres idosas ativas com 80 anos ou mais. Motriz, Rio Claro, v.17 n.1, p.19-25, jan./mar, 2011.

INSTITUTO BRASILEIRO DE GEOGRAFIA E ESTATÍSTICA. IBGE. Síntese de indicadores sociais Uma análise das condições de vida da população brasileira. Rio de Janeiro: IBGE, 2010. Disponível em: $<$ http://www.ibge.gov.br/cidadesat/topwindow.htm?1>. Acesso em 04 jun. 2013.

LOPES, M. A. Pessoas Longevas e Atividade Física: fatores que influenciam a prática. Tese de doutorado, Centro de Desportos, UFSC, Florianópolis, março, 2012. 
MAZO, G.Z.; KRUG, R.R.; VIRTUOSO, J.F.; LOPES, M.A.; TAVARES, A.G. Nível de Atividade Física de Idosos Longevos Participantes de Grupos de Convivências. Boletim Epidemiológico Paulista - BEPA, São Paulo, v.9, n.105, p. 4-14, 2012.

MAZO, G.Z.; LOPES, M.A.; BENEDETTI, T.R.B. Atividade Física e o Idoso: Concepção Gerontológica. Porto Alegre, Editora: Sulina, 2009. 3 ed. Revisada e ampliada. Porto Alegre: Sulina, 2009. 247p.

NETO, M. G.; CASTRO, M. F. Estudo comparativo da independência funcional e qualidade de vida entre idosos ativos e sedentários. Revista Brasileira Medicina Esporte, v.18, n.4, p.234-237, 2012.

ORGANIZAÇÃO MUNDIAL DA SAÚDE. OMS. Envelhecimento ativo: uma política de saúde. Brasília: Organização Pan-Americana de Saúde, 2005.

REIS FILHO, A. D.; COELHO, C. F; VOLTARELLI, F. A.; JUNIOR, J. F.; RAVAGNANI, F. C. P.; et al. Associação entre variáveis antropométricas, perfil glicêmico e lipídico em mulheres idosas. Revista Brasileira Geriatria Gerontologia, Rio de Janeiro, v.14, n.4, p.675-686, 2011.

RIKLI, R E; JONES, C J. Functional fitness normative scores for community-residing older adults, ages 60 94. Journal of Aging and Physical Activity, v.7, p.162-181, 1999. 